Jurnal Keperawatan Silampari

Volume 5, Nomor 1, Desember 2021

e-ISSN: 2581-1975

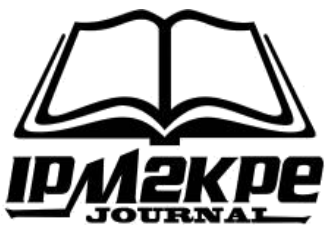

p-ISSN: 2597-7482

DOI: https://doi.org/10.31539/jks.v5i1.2975

\title{
REHABILITASI LATIHAN FISIK TERHADAP PEMULIHAN PASCA STROKE
}

\author{
Rika Diah Pitaloka $^{1}$, I Made Kariasa ${ }^{2}$ \\ Universitas Indonesia ${ }^{1,2}$ \\ rika.diah@ui.ac.id ${ }^{1}$
}

\begin{abstract}
ABSTRAK
Penelitian ini bertujuan untuk mengidentifikasi pengaruh latihan dan aktivitas fisik terhadap pemulihan pasca stroke. Metode dalam penelitian ini adalah literature review dengan mengumpulkan database internasional yaitu PubMed, Proquest, Science Direct, NCBI, Sage Journal, dan Taylor \& Francis. Hasil penelitian menunjukkan total jumlah studi yang direview adalah 12 studi, dengan jumlah pasien sebanyak 701, tipe stroke yang termasuk ke dalam studi ini yaitu; stroke rekuren, iskemik, infark, hemoragik intraserebral dan serangan iskemik transien. Intervensi aktivitas fisik dalam studi literatur ini yaitu latihan aerobik, latihan berjalan, latihan isokinetik, latihan keseimbangan, dan latihan berbasis akuatik. Simpulan, aktivitas dan latihan fisik yang dilakukan secara teratur berpengaruh terhadap pemulihan stroke kronis terutama dapat meningkatkan fungsi motorik, emosional, kesehatan kardiorespirasi dan kualitas hidup.
\end{abstract}

Kata Kunci: Latihan Fisik, Pemulihan, Rehabilitasi, Stroke

\section{ABSTRACT}

This study aims to identify the effect of exercise and physical activity on post-stroke recovery. The method in this study is a literature review by collecting international databases, namely PubMed, Proquest, Science Direct, NCBI, Sage Journal, and Taylor \& Francis. The results showed that the total number of studies reviewed was 12 studies, with 701 patients. The types of stroke included in this study were; recurrent stroke, ischemic, infarction, intracerebral hemorrhage, and transient ischemic attack. Physical activity interventions in this literature study are aerobic exercise, walking exercise, isokinetic training, balance exercise, and aquaticbased exercise. In conclusion, regular physical activity and exercise affect chronic stroke recovery, significantly improving motor function, emotional, cardiorespiratory health, and quality of life.

Keywords: Physical Exercise, Recovery, Rehabilitation, Stroke

\section{PENDAHULUAN}

Stroke dikenal sebagai defisit neurologis fokal. Stroke terjadi apabila terdapat gangguan aliran darah ke otak karena adanya bekuan darah yang menyebabkan stroke iskemik ataupun dikarenakan pecahnya pembuluh darah sehingga menyebabkan stroke hemoragik (Alotaibi, et al, 2020). Ini dialami oleh sekitar 15 juta orang di seluruh dunia dan dianggap sebagai 
penyebab kematian kedua. Diseluruh dunia, stroke merupakan penyebab kematian nomor dua secara global yang mempengaruhi sekitar 13,7 juta orang dan membunuh sekitar 5,5 juta orang setiap tahun (Kuriakose \& Xiao, 2020). Stroke mengubah kehidupan seseorang dengan mempengaruhi fungsi motorik, mobilitas, fungsi kognitif, dan lainnya, yang menyebabkan pembatasan dalam aktivitas dasar kehidupan sehari-hari (Xie et al., 2018).

Stroke mempengaruhi banyak fungsi tubuh seperti; kelumpuhan dan kelemahan, keterampilan motorik kasar, keterampilan motorik halus, ucapan dan bahasa, pengartian, penglihatan, dan emosi (American Heart Association, 2019). Stroke dikaitkan dengan konsekuensi fisik, emosional dan sosial yang mempengaruhi kualitas hidup pasien (Mairami et al., 2019). Sebagian besar pasien yang dipulangkan dari rawat inap pasca stroke memiliki gejala sisa gangguan motorik yang dapat menghambat kemampuan mereka untuk melakukan aktivitas hidup sehari-hari (Nam et al., 2021). Secara global, stroke menyebabkan kecacatan pada $>80$ juta penderitanya, diantara penderita stroke, 25\% dirawat kembali di rumah sakit dalam 90 hari, 73\% mengalami jatuh dalam waktu 6 bulan dan 4 kali kemungkinan patah pinggul ketika mereka jatuh, hampir 50\% penderita stroke tidak terkontrol tekanan darahnya, lebih dari $25 \%$ adalah pengobatan yang tidak persisten, dan $78 \%$ dari waktu penderita stroke dihabiskan untuk tidak bergerak (Duncan, et al, 2020). Kecacatan akibat stroke menyebabkan masalah yang signifikan dalam aspek kehidupan fisik, psikologis, dan sosial, dan mengganggu kualitas hidup penderita stroke (Gezer et al., 2018). Sekitar 70\% dari penderita stroke. Pasien stroke biasanya mengalami juga gangguan emosional dan sosial dalam berbagai derajat. Depresi merupakan perubahan emosi yang paling umum terjadi yang mempengaruhi sekitar 30\% pasien stroke (Lin et al., 2019).

Secara umum, ada tiga tahap pengobatan stroke yaitu; pencegahan, terapi segera setelah stroke, dan rehabilitasi pasca stroke. Rehabilitasi pasca stroke membantu individu mengatasi kecacatan akibat kerusakan stroke (National Institute of Neurological Disorders and Stroke, 2021). 60\% atau sekitar 465.000 individu dengan stroke memerlukan rehabilitasi (Le-Danseur, 2019). Kemajuan dalam rehabilitasi stroke sudah cukup pesat, namun hampir $75 \%$ dari individu dengan stroke tidak mendapatkan pemulihan secara penuh yang mengakibatkan defisit dalam mobilitas, peningkatan resiko jatuh, dan penurunan reintegrasi masyarakat (Linder et al., 2020). Menurut national stroke association, $10 \%$ orang yang terkena stroke dapat pulih sepenuhnya, sedangkan 25\% pulih dengan gangguan ringan dan $40 \%$ lainnya mengalami gangguan sedang hingga berat yang memerlukan perawatan khusus. Waktu pemulihan setelah stroke berbeda untuk setiap pasien, yaitu bisa memakan waktu berminggu-minggu, berbulanbulan, atau bahkan bertahun-tahun.

Beberapa orang pulih sepenuhnya, tetapi yang lain memiliki kecacatan jangka panjang atau seumur hidup. Pemulihan stroke relatif cepat selama 4 minggu pertama setelah pengobatan, dan kemudian melambat antara 3 dan 6 bulan setelah stroke. Selama tiga bulan pertama setelah stroke, otak seperti otak baru yaitu otak siap untuk belajar dan siap untuk membuat koneksi baru. Kemampuan otak untuk menyesuaikan ini dikenal sebagai neuroplastisitas dan memainkan peran penting dalam pemulihan. Dibutuhkan waktu sekitar tiga bulan setelah stroke agar neuroplastisitas kembali kekeadaan yang lebih normal. Tiga bulan setelahnya penderita stroke masih dapat bekerja untuk mendapatkan kembali fungsi dan berlatih untuk peningkatan, tetapi peningkatan tersebut mungkin berjalan lebih lambat (American Stroke Association, 2019). 
Rehabilitasi yang tepat dan berkualitas dapat meningkatkan peluang untuk pemulihan terbaik bagi penderita stroke. Rehabilitasi stroke melibatkan terapi fisik, pekerjaan, bicara dan/atau kognitif (Kuriakose \& Xiao, 2020). Aktivitas fisik dan latihan intensitas sedang atau tinggi direkomendasikan sebagai bagian dari rehabilitasi komprehensif pada fase kronis setelah stroke (Gunnes et al., 2019). Aktivitas fisik didefinisikan sebagai setiap gerakan tubuh yang dihasilkan oleh otot rangka yang menghasilkan pengeluaran energi, seperti yang dilakukan selama aktivitas hidup sehari-hari di rumah, di tempat kerja, selama waktu luang, atau transportasi. Latihan fisik adalah suatu jenis aktivitas fisik dengan ciri-ciri khusus; dilakukan secara berulang-ulang, secara terencana dan terstruktur, untuk meningkatkan atau mempertahankan kebugaran jasmani (Aguiar et al., 2018). Aktivitas fisik penting dilakukan setelah stroke, mengembalikan kapasitas sebelum stroke, serta untuk pencegahan sekunder dengan memperbaiki faktor risiko stroke (Hamre et al., 2021). Manfaat kesehatan dari aktivitas fisik dan olahraga teratur telah dijelaskan dengan baik di banyak literatur. Selain menjadi faktor risiko yang dapat dimodifikasi untuk stroke, aktivitas fisik dan olahraga juga dapat menjadi neuroprotektif. Tingkat aktivitas fisik dan olahraga pasca-stroke memainkan peran penting dalam pemulihan dan neuroplastisitas (Kramer et al., 2019).

Kurangnya aktivitas fisik di antara penderita stroke dapat menyebabkan pemulihan parsial, stroke berulang, atau depresi, sedangkan aktivitas fisik yang teratur dapat mencegah resiko jatuh, kecacatan, dan kehilangan kemandirian. Terlepas dari manfaat aktivitas fisik, penderita stroke sering menghadapi hambatan fisik (misalnya, kelelahan), emosional (misalnya, isolasi sosial), atau lingkungan (misalnya, transportasi) untuk partisipasi aktivitas fisik secara teratur (Taylor-Piliae et al., 2020). Meskipun sudah banyak literatur yang mempromosikan latihan dan aktivitas fisik di selama kehidupan setelah stroke, namun bukti lebih lanjut diperlukan untuk mengeidentifikasi jenis latihan dan aktivitas fisik yang sesuai untuk pasien pasca stroke, efek dari latihan fisik dosis latihan serta mengidentifikasi pengaruh latihan fisik terhadap pemulihan stroke.

Hingga saat ini masih sedikit literature review atau systematic review yang melaporkan tentang efektivitas manajemen latihan fisik terhadap pemulihan pasca stroke. Kemajuan dalam manajemen medis pasien dengan stroke selama dekade terakhir telah secara signifikan mengurangi kematian, namun prevalensi stroke dan jumlah pasien yang hidup dengan konsekuensinya terus meningkat. Sepertiga dari 16 juta pasien di seluruh dunia setiap tahun tetap cacat. Penyakit stroke menimbulkan risiko mortalitas dan morbiditas yang substansial bagi individu dengan beban ekonomi yang meningkat bagi masyarakat. Oleh karena itu, diperlukan strategi rehabilitasi stroke yang lebih efisien seperti latihan fisik dan aktivitas fisik. Berdasarkan alasan diatas, penulis tertarik untuk mengetahui pengaruh latihan fisik terhadap pemulihan pasca stroke.

\section{METODE PENELITIAN}

Studi literature review ini mengumpulkan sebanyak 12 artikel terkait program manajemen latihan fisik pada pasien pasca stroke di berbagai negara. Artikel diambil dari database internasional yaitu PubMed, Proquest, Science Direct, NCBI, Taylor \& Francis, Sage Journal dan Wiley dari tahun 2011-2020. Kata kunci yang digunakan adalah "stroke patients", "stroke recovery", "stroke rehabilitation", "stroke physical activity", "stroke exercise", "stroke physical training". Jenis penelitian yang digunakan oleh penulis dalam literature review ini adalah randomized control trial (11 artikel) dan prospective observational study (1 
artikel). Partisipan dalam penelitian ini adalah pasien stroke dewasa usia >18 tahun, pasien yang didiagnosa stroke berdasarkan pemeriksaan klinis, mengalami gangguan motorik dan psikologis serta tidak ada kontraindikasi untuk melakukan aktivitas fisik Intervensi yang diberikan dalam penelitian ini adalah aktivitas fisik termasuk; latihan aerobik, latihan berjalan, latihan isokinetik, latihan keseimbangan, dan latihan berbasis akuatik.

Perbandingan intervensi yang termasuk ke dalam penelitian ini adalah; latihan berjalan, program rehabilitasi standar, aktivitas fisik standar, latihan peregangan, latihan resistensi progresif. Hasil yang diukur; status fungsional (kapasitas berjalan, keseimbangan, mobilitas, kecepatan berjalan, ketangkasan, ketahanan, kekuatan otot), psikologis (depresi, kecemasan), kognisi, pengeluaran energi, kebugaran kardiorespirasi, profil aktivitas individu dan kualitas hidup pasien.

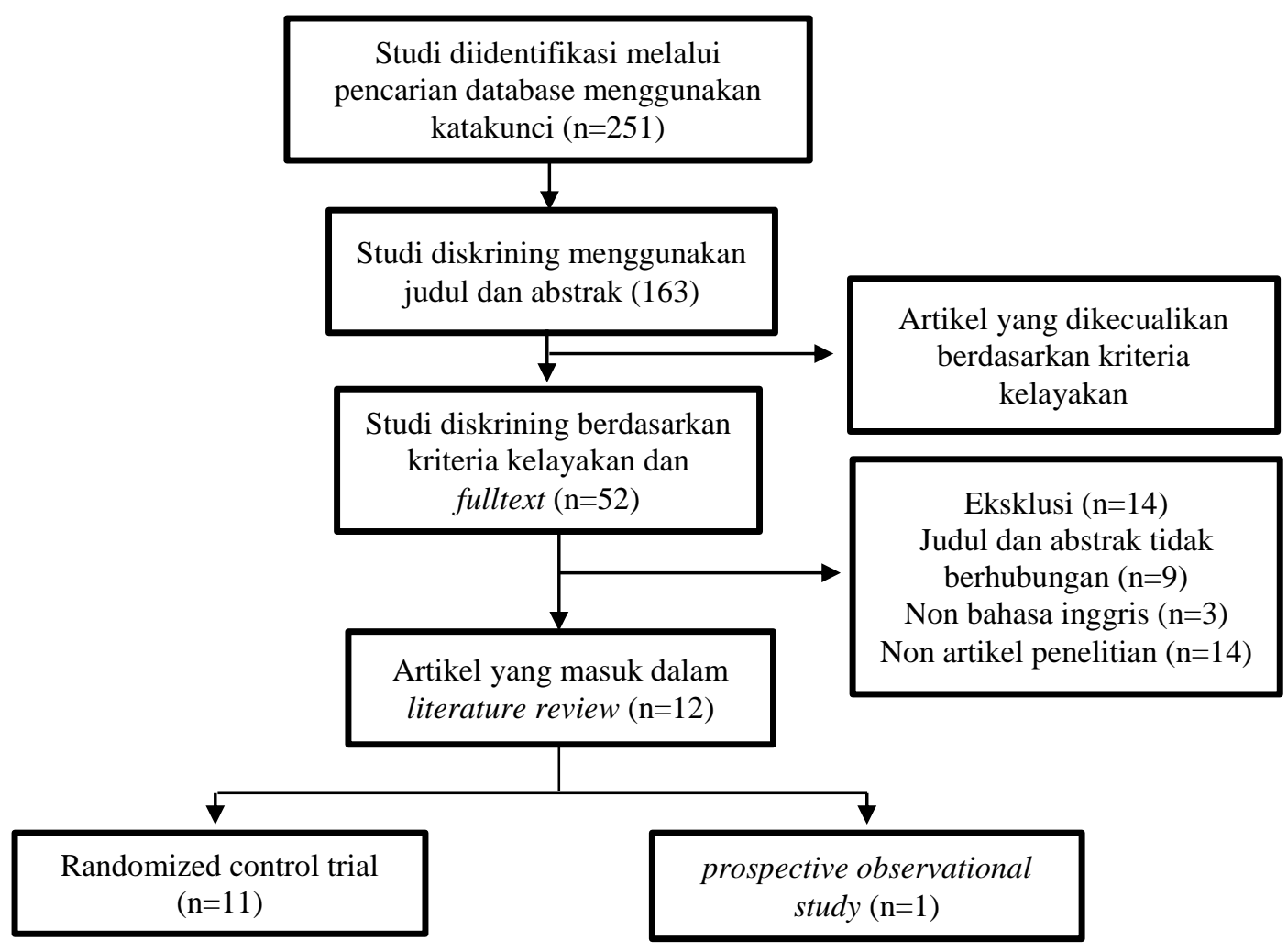

Gambar. 1

Alur Pencarian Literatur

Kriteria studi yang dimasukkan oleh penulis terhadap kriteria seleksi adalah sebagai berikut; 1) artikel yang memiliki judul dan isi yang relevan dengan tujuan penelitian; 2) berbahasa inggris dan full text; 3) artikel penelitian yang dipublikasikan ada 2011-2021. Sedangkan kriteria eksklusi dari artikel ini yaitu; 1) tidak memiliki struktur artikel yang lengkap. 


\section{HASIL PENELITIAN}

Tabel. 1

Karakteristik Studi

\begin{tabular}{|c|c|c|c|}
\hline $\begin{array}{c}\text { Pengarang, Judul, Jenis } \\
\text { Literatur }\end{array}$ & Tahun & Tujuan & Hasil Temuan \\
\hline $\begin{array}{l}\text { Vahlberg at al., } \\
\text { Effects on Walking } \\
\text { Performance and Lower } \\
\text { Body Strength by Short } \\
\text { Message Service } \\
\text { Guided Training after } \\
\text { Stroke or Transient } \\
\text { Ischemic Attack (The } \\
\text { Strokewalk Study): A } \\
\text { Randomized Controlled } \\
\text { Trial, } \\
\text { Randomized Controlled } \\
\text { Trial }\end{array}$ & 2020 & $\begin{array}{l}\text { Untuk mengevaluasi } \\
\text { apakah pesan yang } \\
\text { disampaikan melalui } \\
\text { ponsel setiap hari dengan } \\
\text { instruksi pelatihan selama } \\
\text { tiga bulan, meningkatkan } \\
\text { aktivitas fisik dan } \\
\text { mobilitas keseluruhan } \\
\text { pada pasien segera setelah } \\
\text { stroke atau serangan } \\
\text { iskemik transien }\end{array}$ & $\begin{array}{l}\text { Tersapat peningkatan yang } \\
\text { signifikan dalam tes berjalan } \\
\text { enam menit }(\mathrm{P}=0.037) \text {; } \\
\text { Terdapat peningkatan dalam tes } \\
\text { berdiri di kursi }(\mathrm{P}=0.034) \text {; } \\
\text { Terdapat peningkatan rata-rata } \\
\text { jumlah langkah, }(\mathrm{P}=0,001) \text {. }\end{array}$ \\
\hline $\begin{array}{l}\text { Aguaiar et al., } \\
\text { Effects of Aerobic } \\
\text { Training on Physical } \\
\text { Activity in People with } \\
\text { Stroke: A Randomized } \\
\text { Controlled Trial, } \\
\text { Randomized Controlled } \\
\text { Trial }\end{array}$ & 2020 & $\begin{array}{l}\text { Untuk menyelidiki efek } \\
\text { pelatihan treadmill aerobik } \\
\text { pada tingkat aktivitas fisik } \\
\text { dan waktu yang } \\
\text { dihabiskan dalam aktivitas } \\
\text { pengeluaran energi rendah } \\
\text { (hasil utama), serta } \\
\text { kebugaran kardiorespirasi, } \\
\text { daya tahan, depresi, } \\
\text { mobilitas, kualitas hidup } \\
\text { dan partisipasi (hasil } \\
\text { sekunder) setelah stroke }\end{array}$ & $\begin{array}{l}\text { Terdapat peningkatan kualitas } \\
\text { hidup yang signifikan pada } \\
\text { kelompok yang diberikan latihan } \\
\text { aerobik; } \\
\text { Terdapat penurunan skor depresi } \\
\text { Terdapat daya tahan dan } \\
\text { mobilitas pada kedua kelompok. }\end{array}$ \\
\hline $\begin{array}{l}\text { Gunnes et al., } \\
\text { Associations Between } \\
\text { Adherence to the } \\
\text { Physical Activity and } \\
\text { Exercise Program } \\
\text { Applied in the LAST } \\
\text { Study and Functional } \\
\text { Recovery After Stroke, } \\
\text { Randomized Controlled } \\
\text { trial Life After Stroke } \\
\text { (LAST) }\end{array}$ & 2019 & $\begin{array}{lr}\text { Untuk } & \text { menyelidiki } \\
\text { hubungan } & \text { antara } \\
\text { kepatuhan } & \text { peserta } \\
\text { terhadap aktivitas fisik dan } \\
\text { program latihan setelah } \\
\text { stroke dan pemulihan } \\
\text { fungsional 18 bulan } \\
\text { setelah inklusi }\end{array}$ & $\begin{array}{l}\text { Terdapat hubungan yang } \\
\text { signifikan antara kepatuhan } \\
\text { terhadap aktivitas dan laihan fisik } \\
\text { dengan peningkatan fungsi } \\
\text { motorik (P 0.007); } \\
\text { Kepatuhan terhadap aktivitas fisik } \\
\text { dan latihan gabungan secara } \\
\text { signifikan dapat meningkatkan } \\
\text { kapasitas berjalan, keseimbangan } \\
\text { dan ADL. }\end{array}$ \\
\hline $\begin{array}{l}\text { Aidar et al., } \\
\text { A Randomized Trial of } \\
\text { the Effects of An } \\
\text { Aquatic Exercise } \\
\text { Program on Depression, } \\
\text { Anxiety Levels, and } \\
\text { Functional Capacity of } \\
\text { People Who Suffered an } \\
\text { Ischemic Stroke, } \\
\text { Randomized Trial }\end{array}$ & 2018 & $\begin{array}{l}\text { Untuk melakukan } \\
\text { Percobaan Acak dari Efek } \\
\text { Program Latihan Akuatik } \\
\text { pada Depresi, Tingkat } \\
\text { Kecemasan, dan Kapasitas } \\
\text { Fungsional Orang yang } \\
\text { Menderita Stroke Iskemik }\end{array}$ & $\begin{array}{l}\text { Terdapat penurunan skor } \\
\text { kecemasan dan depresi yang } \\
\text { signifikan sesudah diberikan } \\
\text { intervensi program latihan akuatik } \\
(\mathrm{P} \leq 0.05) \text {. } \\
\text { Ditemukan pengaruh program } \\
\text { akuatik yang signifikan terhadap } \\
\text { kapasitas fungsional. }\end{array}$ \\
\hline
\end{tabular}




\begin{abstract}
Coroian et al., Upper Limb Isokinetic Strengthening Versus Passive Mobilization in Patients with Chronic Stroke: A Randomized Controlled Trial, Randomized Controlled Trial
\end{abstract}

$2017 \begin{aligned} & \text { Untuk menilai manfaat } \\ & \text { penguatan isokinetik } \\ & \text { ekstremitas atas (UL) pada } \\ & \text { pasien dengan stroke } \\ & \text { kronis dibandingkan } \\ & \text { dengan mobilisasi pasif }\end{aligned}$

Pada evaluasi V1, tidak terdapat perbedaan skor skor kekuatan ekstremitas secara signifikan antara kedua kelompok;

Pada evaluasi V2 dan V3, tidak ditemukan perbedaan yang signifikan dalam perolehan skor penguatan ekstremitas atas antara kedua kelompok;

Tidak ada perbedaan signifikan dalam perubahan skor BBT, skor spastisitas, torsi puncak, dan indeks barthel dari V0 ke V1, V2 dan V3 antara kedua kelompok.

\begin{tabular}{|c|c|c|c|}
\hline $\begin{array}{l}\text { Lund et al., } \\
\text { Balance and Walking } \\
\text { Performance are } \\
\text { Improved rafter } \\
\text { Resistance and Aerobic } \\
\text { Training in Persons with } \\
\text { Chronic Stroke }\end{array}$ & 2017 & $\begin{array}{l}\text { Untuk menyelidiki } \\
\text { pengaruh berbagai jenis } \\
\text { latihan fisik pada kinerja } \\
\text { keseimbangan dan apakah } \\
\text { peningkatan } \\
\text { keseimbangan berkorelasi } \\
\text { dengan peningkatan } \\
\text { kinerja berjalan }\end{array}$ & $\begin{array}{l}\text { Terdapat peningkatan } \\
\text { keseimbangan yang signifikan. } \\
\text { Terdapat peningkatan tingkat } \\
\text { penyerapan oksigen puncak } \\
\text { sebesar 15,5 }(6,0-25,0) \text {. } \\
\text { Meningkatkan kekuatan ekstensor } \\
\text { lutut non-paretic } \\
\text { Meningkatkan keseimbangan dan } \\
\text { jarak berjalan secara signifikan }\end{array}$ \\
\hline $\begin{array}{l}\text { Vahlberg et al., } \\
\text { Short-Term and Long- } \\
\text { Term Effects of a } \\
\text { Progressive Resistance } \\
\text { and Balance Exercise } \\
\text { Program in Individuals } \\
\text { with Chronic Stroke: A } \\
\text { Randomized Controlled } \\
\text { Trial, }\end{array}$ & 2016 & $\begin{array}{l}\text { Untuk mengevaluasi efek } \\
\text { latihan resistensi dan } \\
\text { keseimbangan progresif } \\
\text { (PRB) pada fungsi fisik } \\
\text { dan psikologis individu } \\
\text { pasca stroke }\end{array}$ & \begin{tabular}{lrr} 
Terdapat & \multicolumn{2}{c}{ perbaikan } \\
keseimbangan $(0.001)$ dan \\
kecepatan berjalan $(\mathrm{P}=0.012)$ \\
signifikan pada & kelompok \\
intervensi & dibandingkan \\
kelompok kontrol. &
\end{tabular} \\
\hline $\begin{array}{l}\text { Sandberg et al., } \\
\text { Effects of Twice- } \\
\text { Weekly Intense Aerobic } \\
\text { Exercise in Early } \\
\text { Subacute Stroke: A } \\
\text { Randomized Controlled } \\
\text { Trial, } \\
\text { Randomized Controled } \\
\text { Trial }\end{array}$ & 2016 & $\begin{array}{l}\text { Untuk menguji efek dari } \\
12 \text { minggu latihan aerobik } \\
\text { intensif dua kali seminggu } \\
\text { pada fungsi fisik dan } \\
\text { kualitas hidup setelah } \\
\text { stroke subakut }\end{array}$ & $\begin{array}{l}\text { Terdapat peningkatan kapasistas } \\
\text { aerobik yang signifikan }(\mathrm{P}=.006) \\
\text { Terdapat peningkatan jarak } \\
\text { berjalan }(\mathrm{P}=.011) \\
\text { Terdapat peningkatan kecepatan } \\
\text { berjalan }(\mathrm{P}<.001) \\
\text { Terdapat peningkatan mobilitas } \\
\text { fungsional ( } \mathrm{P}<.001) \text {, dan } \\
\text { peningkatan keseimbangan pada } \\
\text { kaki kanan dan kiri }(\mathrm{P}<.001 \text { dan } \\
\mathrm{P}=.022 \text { berturut-turut }) .\end{array}$ \\
\hline $\begin{array}{l}\text { Marzolini et al., } \\
\text { The Effects of an } \\
\text { Aerobic and Resistance } \\
\text { Exercise Training } \\
\text { Program on Cognition } \\
\text { Following Stroke, }\end{array}$ & 2012 & $\begin{array}{l}\text { Untuk mengevaluasi efek } \\
\text { dari program latihan } 6 \\
\text { bulan AT+RT pada } \\
\text { kognisi pada pasien yang } \\
\text { terdaftar secara berurutan } \\
\text { dengan gangguan motorik } \\
10 \text { minggu pasca stroke }\end{array}$ & $\begin{array}{l}\text { Terdapat meningkatan } \mathrm{Vo}_{2} \text { max } \\
\text { yang signifikan }(\mathrm{P}=<0.001) ; \\
\text { Terdapat peningkatan kekuatan } \\
\text { otot tungkai bawah }(\mathrm{P}=<0.007) \text {; } \\
\text { Terdapat peningkatan skor MoCA } \\
\text { secara signifikan }(\mathrm{P}=<0.001) \text {. }\end{array}$ \\
\hline
\end{tabular}




\section{Karakteristik Studi}

Total jumlah studi dalam literature review ini yaitu berjumlah 12 studi, dengan jumlah pasien sebanyak 701, tipe stroke yang termasuk ke dalam studi ini yaitu; stroke rekuren, iskemik, infark, hemoragik intraserebral dan serangan iskemik transien. Intervensi aktivitas fisik dalam studi literatur ini yaitu latihan aerobik, latihan berjalan, latihan isokinetik, latihan keseimbangan, dan latihan berbasis akuatik. Studi yang diambil oleh peneliti mayoritas berasal dari negara Swedia dan Norwegia, kemudian disusul oleh Canada, Brazil, USA, Denmark, Perancis dan Korea. Mayoritas partisipan dalam studi literature review ini diambil dari rumah sakit komunitas dan unit rehabilitasi. Rata-rata usia partisipan dalam studi ini yaitu dari 48-79 tahun. Hasil dari telaah artikel dalam literature review ini menunjukkan bahwa latihan fisik bermanfaat untuk pemulihan stroke secara fisik dan psikososial.

\section{Jenis Intervensi Latihan Fisik}

Jenis intervensi latihan fisik yang digunakan dalam literarure review ini adalah latihan jalan kaki terprogram $(n=1)$; program latihan aerobik seperti latihan berjalan, bersepeda tegak, latihan siklus ergometer, treadmill $(n=5)$; aktivitas fisik seperti berjalan, melakukan aktivitas rumah tangga dan berkebun $(n=1)$; latihan berbasis akuatik dengan kegiatan berjalan kaki di dalam kolam renang, mengayuh, latihan pernapasan, membuat gelembung di dalam air, berenang miring $(n=1)$; latihan isokinetic strengthening $(n=1)$; latihan ambulasi $(n=1)$, latihan ketahanan dan aerobik $(n=1)$, latihan ketahanan dan latihan keseimbangan terprogram $(n=1)$.

\section{Durasi dan Intensitas Program Latihan}

Durasi dan intensitas intervensi dalam literature review ini adalah dimulai dari 10 menit latihan sebanyak 3 kali sehari dilakukan setiap hari selama 3 bulan; 20-40 menit/ sesi, dilakukan 3 kali dalam seminggu selama 12 minggu; 40 menit/sesi selama 12 minggu; 40 menit, dilakukan tiga kali seminggu selama 6 bulan; 45-60 menit, dilakukan 2 kali seminggu selama 12 minggu; 45-60 menit dilakukan 3 kali seminggu selama 6 minggu, 60 menit dilakukan 3 kali seminggu, selama 12 minggu; 75 menit dilakukan 2-3 kali seminggu selama 4 minggu, 90 menit dilakukan 3 kali seminggu selama 24 minggu.

\section{Pengaruh Intervensi Latihan Fisik terhadap Fungsi Motorik}

8 artikel yang mengukur pengaruh intervensi latihan fisik terhadap moblitas melaporkan bahwa latihan fisik dapat meningkatkan kekuatan otot, kinerja berjalan, keseimbangan kaki, peningkatan dalam jumlah langkah, peningkatan kemampuan untuk berdiri serta meningkatkan mobilitas dan fungsi motoric.

\section{Pengaruh Intervensi Latihan Fisik terhadap Tingkat Depresi dan Kecemasan}

Tiga artikel dalam studi literature review ini melaporkan bahwa latihan fisik dapat meurunkan tingkat depresi dan kecemasan.

\section{Pengaruh Intervensi Latihan Fisik terhadap Kebugaran Kardiorespirasi}

Terdapat empat artikel dalam studi literature ini yang menemukan bahwa latihan fisik dapat meningkatkan kebugaran kardiorespirasi yang ditandai dengan peningkatan kapasitas aerobik dan peningkatan $\mathrm{VO}_{2}$ max. 


\section{Pengaruh Intervensi Latihan Fisik terhadap Kualitas Hidup}

Terdapat empat artikel dalam studi literature review ini melaporkan bahwa latihan fisik dapat meurunkan tingkat depresi dan kecemasan, dan meningkatkan kualitas hidup.

\section{PEMBAHASAN}

\section{Meningkatkan Fungsi Motorik}

Pemulihan motorik pasca stroke terjadi selama 10 minggu pertama dan kapasitas pemulihan secara langsung terkait dengan derajat keparahan awal stroke (Moucheboeuf et al., 2020). Secara keseluruhan latihan fisik merupakan intervensi yang efektif untuk pemulihan stroke karena beberapa alasan. Pertama, melalui program manajemen latihan fisik pasien dapat memperoleh lebih banyak kemandirian dengan menjadi aktif, pasien dapat memperoleh cara baru untuk meningkatkan kekuatan otot dan mobilitas dengan menggerakkan dan menggunakan bagian-bagian tubuh secara aktif dan teratur. Pasien dapat berlatih berjalan, mengangkat barang dan menggunakan tangan. Pengulangan latihan dan aktivitas fisik ini dapat membantu pasien untuk menjadi lebih kuat dan mempelajari kembali keterampilan untuk tugas-tugas penting seperti berpakaian, memasak, dan bepergian (Stroke Association, 2020).

Peningkatan jumlah aktivitas fisik sebagai rehabilitasi pasca stroke semakin diakui. Penderita stroke harus dapat meluangkan waktu untuk berlatih tugas sehari-hari, berjalan dan latihan aktivitas fisik lainnya agar dapat mencapai pemulihan yang optimal. Salah satu aktivitas fisik yang dapat dilakukan yaitu dengan mendorong kursi roda manual secara mandiri. Berdasarkan studi pada 74 pasien stroke yang menggunakan kursi roda, menemukan bahwa aktivitas fisik dengan mendorong kursi roda manual secara sendiri dalam kehidupan sehari-hari dengan jarak minimal $\geq 0.60 \mathrm{~km} /$ hari dan $\geq 2500$ langkah/hari menunjukkan pemulihan fungsional yang signifikan. Aktifitas fisik dengan mendorong kursi roda sendiri yang dapat dilakukan oleh penderita stroke non-ambulatory dalam kehidupan sehari-hari. Sementara itu, mendoromg kursi roda manual yang dilakukan oleh pasien sendiri adalah cara agar penderita stroke non-ambulatory bisa mendapatkan waktu aktivitas fisik ekstra mandiri ketika mereka tidak memiliki seseorang untuk membantu berjalan (Kimura et al., 2020).

Kepatuhan terhadap aktivitas fisik dan program latihan terhadap pemulihan fungsional setelah stroke secara signifikan dikaitkan dengan peningkatan fungsi motorik, keseimbangan, dan hasil fungsional. Jenis aktivitas fisik yang diberikan dalam penelitian tersebut termasuk berjalan, melakukan pekerjaan rumah tangga dan berkebun. Penelitian tersebut adalah yang pertama yang menunjukkan bahwa kepatuhan yang lebih baik terhadap aktivitas fisik dan program latihan dikaitkan dengan pemulihan fungsional yang lebih baik selama periode tindak lanjut 18 bulan dalam studi kohort populasi besar terhadap penderita stroke yang tinggal di komunitas setelah stroke (Gunnes et al., 2019). Studi terdahulu mengidentifikasi tentang efektivitas latihan fisik latihan aerobik dengan berjalan di atas tanah atau treadmill dapat meningkatkan kemampuan berjalan pada pasien pasca stroke (Boyne et al., 2017).

\section{Menurunkan Depresi dan Kecemasan Pasca Stroke}

Stroke telah dikaitkan dengan beberapa gangguan psikologis, termasuk kecemasan dan depresi. Depresi pasca stroke adalah salah satu komplikasi neuropsikiatri yang paling umum setelah stroke. Beberapa penelitian telah menunjukkan bahwa latihan fisik dapat menjadi pengobatan pelengkap untuk depresi pasca stroke (Zhang et al., 2021). Latihan aerobik merupakan salah satu intervensi terapeutik yang memungkinkan untuk gangguan mood yang 
kompleks. Latihan aerobik berupa latihan lari diketahui dapat menginduksi penurunan gejala depresi dan perubahan suasana hati. mendemonstrasikan latihan lari sebagai latihan aerobik untuk mengurangi gejala depresi (Keating et al., 2018). Berdasarkan studi program latihan akuatik intensitas rendah sebanyak dua kali seminggu efektif untuk mengurangi depresi dan kecemasan, meningkatkan otonomi fungsional dan mengurangi stres oksidatif pada individu lanjut usia yang depresi (Da-Silva et al., 2019). Paprocka-Borowicz et al., (2021) mengatakan bahwa terapi fisik merupakan metode yang efektif untuk mengobati depresi pasca stroke. Mereka melakukan penelitian pada 40 pasien stroke, yang bertujuan untuk mengevaluasi dampak aktivitas fisik dan status sosial ekonomi pasien terhadap efektivitas pemulihan dari depresi dan tingkat keparahan gejala depresi. Dari penelitian tersebut dilaporkan bahwa terapi fisik memiliki pengaruh positif pada kondisi mental, dimana terapi fisik dapat mengubah tingkat keparahan gejala kecemasan dan gangguan depresi.

Aktivitas fisik secara teratur juga dapat membantu meningkatkan kesejahteraan emosional dan kepercayaan diri. Melakukan olahraga dengan teratur dapat membantu mengurangi perasaan cemas dan stres. Hal ini juga dapat membantu membangun kepercayaan diri pasien tentang dirinya sendiri (Stroke Association, 2020). Latihan fisik atau olahraga secara teratur dapat meningkatkan kualitas hidup, kemampuan untuk bekerja dan bersantai, dan mengurangi kejadian stroke baru. Aktivitas fisik adalah cara terbaik untuk mengurangi stres pada orang dengan disabilitas dan cenderung meningkatkan aspek sosial dan emosional dari mereka yang berlatih secara teratur (Aidar et al., 2018).

Studi terbaru menemukan bahwa program latihan akuatik selama 12 minggu pada penderita stroke dapat menurunkan tingkat depresi dan kecemasan serta peningkatan kapasitas fungsional pada orang yang menderita stroke iskemik bahkan pada subjek yang telah menderita stroke lebih dari setahun sebelumnya. Aktivitas fisik yang diberikan dalam latihan akuatik tersebut mencakup; berenang miring, berjalan kaki di kolam renang, mengayuh, melakukan pendakian dan penurunan kolam renang, dan latihan membuat gelembung air (Aidar et al., 2018). Latihan fisik dapat menurunkan gejala depresi melalui sejumlah mekanisme. Misalnya, aksis hipotalamus hipofisis-adrenal mungkin disregulasi pada individu dengan depresi, yang mengakibatkan peningkatan kadar kortisol. Olahraga dapat meningkatkan regulasi respons hipotalamus hipofisis-adrenal. Depresi juga berdampak langsung dan tidak langsung pada fungsi kekebalan tubuh dan olahraga teratur dapat berfungsi sebagai stimulus nonfarmakologis untuk meningkatkan fungsi kekebalan. Selanjutnya, kontak sosial melalui latihan kelompok mungkin bermanfaat bagi individu dengan depresi pasca stroke (Winstein et al., 2019).

\section{Meningkatkan Kebugaran Kardiorespirasi (Cardiorespiratory Fitness)}

Kebugaran kardiorespirasi (cardiorespiratory fitness) adalah salah satu prediktor terkuat risiko stroke yang diukur sebagai konsumsi oksigen puncak $\left(\mathrm{VO}_{2}\right.$ peak). Individu dengan stroke memiliki sekitar 50\% penurunan kebugaran kardiorespirasi. Setelah stroke, biasanya terjadi penurunan kapasitas aerobik yang terus berlanjut selama enam bulan berikutnya dan seringkali tetap menurun setelahnya. Kebanyakan pasien tidak dapat pulih secara spontan ke tingkat aerobik sebelumnya. Pengambilan oksigen maksimum $\left(\mathrm{VO}_{2}\right.$ max $)$ menurun menjadi 10-17 ml/kg/menit dalam 0-30 hari setelah stroke dan tidak meningkat hingga lebih dari 20 $\mathrm{ml} / \mathrm{kg} / \mathrm{menit}$ setelah enam bulan pasca stroke. Hal ini lebih rendah $25-45 \%$ dari VO2 max pada individu yang sehat. Penurunan $\mathrm{VO}_{2}$ max ini dapat mempengaruhi rehabilitasi pasien stroke 
yang membutuhkan kapasitas aerobik yang lebih besar untuk berjalan dan melakukan aktivitas hidup sehari-hari.

Hal ini sejalan dengan hasil yang dilaporkan oleh studi systematic review dan meta analysis terbaru bahwa latihan fisik secara signifikan meningkatkan kebugaran respirasi dalam sepuluh percobaan (rata-rata $\mathrm{ES}=.41,95 \% \mathrm{CI}=.25$ sampai $.56, \mathrm{P}<.0001$ ) dengan peningkatan absolut kebugaran kardiorespirasi adalah $12 \%$ (Lee \& Stone, 2019). Sebuah tinjauan sistematis baru-baru ini dengan meta-analisis termasuk 15 studi, dan total 598 peserta, menunjukkan bahwa latihan aerobik sedang dan kuat dengan siklus ergometer dan treadmill dapat meningkatkan skor $\mathrm{VO}_{2}$ max pada pasien pasca stroke, dan bahwa intensitas yang lebih tinggi akan dikaitkan dengan hasil yang lebih baik (Da-Campo et al., 2019).

\section{Meningkatkan Kualitas Hidup}

Penurunan kualitas hidup dan penurunan aktivitas fisik sehari-hari sering dilaporkan pada pasien pasca stroke. Kualitas hidup adalah konstruksi multifactorial yang mencakup persepsi subjektif dari domain fisik, psikologis, sosial dan lingkungan. Kualitas hidup telah digunakan sebagai indikator penting untuk mengetahui keefektifan rehabilitasi stroke selama lebih dari 3 dekade (Bello et al., 2020). Partisipasi sosial telah ditemukan berkorelasi dengan kesehatan fisik, kesehatan mental, isolasi sosial, serta kualitas hidup jangka panjang pada individu yang pasca stroke (Misawa \& Kondo, 2018). Ini juga dapat mempengaruhi persepsi seseorang tentang kesejahteraan emosional mereka. Lebih penting lagi, pasien stroke sering melihat tingkat partisipasi sosial mereka sebagai aspek sentral dari keberhasilan pemulihan (Schwarz et al., 2018). Pasien yang tidak dapat berpartisipasi secara sosial setelah stroke berada pada peningkatan risiko stroke berulang, depresi, dan kematian selama pemulihan mereka. Perasaan isolasi sosial juga dikaitkan dengan pemulihan status fungsional yang lebih lambat (Schnitzler et al., 2019).

Meningkatkan partisipasi dalam kegiatan latihan fisik akan membuat pasien stroke dapat terlibat dalam aktivitas fisik rutin mereka, dengan demikian mereka harus meningkatkan jumlah waktu yang dihabiskan untuk aktivitas tersebut. Peningkatan kemandirian fungsional pasien dapat mengarah dapat mengarah pada kemampuan fisik yang lebih baik untuk berintegrasi kembali ke dalam kehidupan sosial. Partisipasi sosial telah ditemukan berkorelasi dengan kesehatan fisik, kesehatan mental, isolasi sosial, serta kualitas hidup jangka panjang untuk pasien pasca stroke. Intervensi yang melibatkan latihan sebagian atau sendiri, telah terbukti lebih efektif dalam meningkatkan partisipasi sosial daripada intervensi tanpa latihan (Zhang et al., 2020). Olahraga teratur cenderung meningkatkan kualitas hidup, kemampuan untuk bekerja dan bersantai, dan mengurangi kejadian stroke baru dan akibatnya hilangnya kondisi fisik (Aidar et al., 2018).

Intervensi yang melibatkan latihan sebagian atau sendiri, terbukti lebih efektif dalam meningkatkan partisipasi sosial daripada intervensi berbasis non-olahraga. Hal ini menunjukkan bahwa olahraga dapat menjadi elemen yang bermanfaat dalam mendapatkan kembali partisipasi sosial bagi penderita stroke (Zhang et al., 2020). 


\section{SIMPULAN}

Studi ini merupakan studi literature review pertama yang mengkaji tentang pengaruh intervensi berbasis latihan fisik terhadap pemulihan stroke. Studi literature ini menemukan bahwa aktivitas dan latihan fisik yang dilakukan secara teratur berpengaruh terhadap pemulihan stroke kronis terutama dapat meningkatkan fungsi motorik, emosional, kesehatan kardiorespirasi dan kualitas hidup.

\section{SARAN}

Perawat memiliki peran khusus dalam mengedukasi pasien stroke tentang pentingnya menjaga aktivitas dan latihan fisik untuk membantu meningkatkan pemulihan pasca stroke, dalam hal ini perawat dapat bekerja sama dengan pasien dan mereka dan keluarga pasien. Untuk itu perawat memerlukan pengetahuan tentang berbagai pilihan yang tersedia untuk rehabilitasi stroke, dan harus menyadari kekuatan pilihan tertentu, agar lebih mampu memfasilitasi dalam proses pengambilan keputusan. Namun, perawat mungkin dibatasi dalam memilih modalitas latihan yang sesuai untuk pasien pasca stroke, yang dapat menunda pasien untuk mencapai terapi terbaik untuk meningkatkan pemulihan. Hasil dari penelitian ini dapat memberikan informasi tentang pemilihan latihan dan mempromosikan keberhasilan penerapan intervensi rehabilitatif.

\section{DAFTAR PUSTAKA}

Aguiar, L. T., Nadeau, S., Britto, R. R., Teixeira-Salmela, L. F., Martins, J. C., \& Faria, C. D. C.. (2018). Effects of Aerobic Training on Physical Activity in People with Stroke: Protocol for a Randomized Controlled trial. Trials, 19(1). doi:10.1186/s13063-018-2823-

Aguiar, L. T., Nadeau, S., Britto, R. R., Teixeira-Salmela, L. F., Martins, J. C., Samora, G. A. R., Da Silva Júnior, J. A., \& Faria, C. D. C. D. M. (2020). Effects of Aerobic Training on Physical Activity in People with Stroke: A Randomized Controlled Trial. NeuroRehabilitation, 46(3), 391-401. https://doi.org/10.3233/NRE-193013

Aidar, F. J., Oliveira, J. O. R., Matos, G. D., Chilibeck, P. D., De-Soüza, R. F., Carneiro, A. L., \& Reis, M. V. (2018). A Randomized Trial of the Effects of An Aquatic Exercise Program on Depression, Anxiety Levels, and Functional Capacity of People Who Suffered an Ischemic Stroke. Journal of Sports Medicine and Physical Fitness, 58(7-8), 1171-1177. https://doi.org/10.23736/S0022-4707.17.07284-X

Alotaibi, S. M., Alotaibi, H. M., Alolyani, A. M., Abu Dali, F. A., Alshammari, A. K., Alhwiesh, A. A., Gari, D. M., Khuda, I. K. M. Q., \& Vallabadoss, C. A. (2021). Assessment of the Stroke-Specific Quality-of-Life Scale in Kfhu, Khobar a Prospective Cross-Sectional Study. Neurosciences, 26(2), 171-178. https://doi.org/10.17712/nsj.2021.2.20200126

American Heart Association. (2019). Heart Disease and Stroke Statistics-2019 At-a-Glance Heart Disease, Stroke and other Cardiovascular Diseases. https://healthmetrics.heart.org/wp-content/uploads/2019/02/At-A-Glance-Heart-Diseaseand-Stroke-Statistics--2019.pdf

Bello, U. M., Chutiyami, M., Salihu, D., Abdu, S. I., Tafida, B. A., Jabbo, A. A., Gamawa, A., Umar, L., Lawan, A., Miller, T., \& Winser, S. J. (2021). Quality of Life of Stroke Survivors in Africa: A Systematic Review and Meta-Analysis. Quality of Life Research, 30(1). https://doi.org/10.1007/s11136-020-02591-6 
Boyne, P., Welge, J., Kissela, B., \& Dunning, K. (2017). Factors Influencing the Efficacy of Aerobic Exercise for Improving Fitness and Walking Capacity After Stroke. Archives of Physical Medicine and Rehabilitation, 98(3), 581-595. doi:10.1016/j.apmr.2016.08.484

Coroian, F., Jourdan, C., Bakhti, K., Palayer, C., Jaussent, A., Picot, M. C., Mottet, D., Julia, M., Bonnin, H. Y., \& Laffont, I. (2018). Upper Limb Isokinetic Strengthening Versus Passive Mobilization in Patients with Chronic Stroke: A Randomized Controlled Trial. Archives of Physical Medicine and Rehabilitation, 99(2), 321-328. https://doi.org/10.1016/j.apmr.2017.08.490

Da-Campo, L., Hauck, M., Marcolino, M. A. Z., Pinheiro, D., Plentz, R. D. M., \& Cechetti, F. (2019). Effects of Aerobic Exercise Using Cycle Ergometry on Balance and Functional Capacity in Post-Stroke Patients: A Systematic Review and Meta-Analysis of Randomised Clinical Trials. Disability and Rehabilitation, 43(11), 1558-1564. doi:10.1080/09638288.2019.16702

Da-Silva, L. A., Tortelli, L., Motta, J., Menguer, L., Mariano, S., Tasca, G., Silveira, G. de B., Pinho, R. A., \& Silveira, P. C. L. (2019). Effects of Aquatic Exercise on Mental Health, Functional Autonomy and Oxidative Stress in Depressed Elderly Individuals: A Randomized Clinical Trial. Clinics, 74, 1-7. https://doi.org/10.6061/clinics/2019/e322

Duncan, P. W., Bushnell, C., Sissine, M., Coleman, S., Lutz, B. J., Johnson, A. M., \& Stein, J. (2020). Comprehensive Stroke Care and Outcomes. Stroke, 52(1), 385-393. DOI:10.1161/strokeaha.120.02967

Gezer, H., Karaahmet, O. Z., Gurcay, E., Dulgeroglu, D., \& Cakci, A. (2018). The Effect of Aerobic Exercise on Stroke Rehabilitation. Irish Journal of Medical Science (1971). DOI:10.1007/s11845-018-1848-4

Gunnes, M., Indredavik, B., Langhammer, B., Lydersen, S., Ihle-Hansen, H., Dahl, A. E., \& Askim, T. (2019). Associations Between Adherence to the Physical Activity and Exercise Program Applied in the LAST Study and Functional Recovery After Stroke. Archives of Physical Medicine and Rehabilitation, 100(12), 2251-2259. https://doi.org/10.1016/j.apmr.2019.04.023

Hamre, C., Fure, B., Helbostad, J. L., Wyller, T. B., Ihle-Hansen, H., Vlachos, G., Ursin, M. H., \& Tangen, G. G. (2021). Factors Associated with Level of Physical Activity After Minor Stroke. Journal of Stroke and Cerebrovascular Diseases, 30(4). https://doi.org/10.1016/j.jstrokecerebrovasdis.2021.105628

Haverinen-Shaughnessy, U., Turunen, M., Metsämuuronen, J., Palonen, J., Putus, T., Kurnitski, J., \& Shaughnessy, R. J. (2012). Sixth Grade Pupils' Health and Performance and Indoor Environmental Quality in Finnish School Buildings. British Journal of Educational Research, 2(1), 42-58. https://www.researchgate.net/publication/253233983

Keating, L. E., Becker, S., McCabe, K., Whattam, J., Garrick, L., Sassi, R. B., Frey, B. N., \& McKinnon, M. C. (2018). Effects of a 12-Week Running Programme in Youth and Adults with Complex Mood Disorders. BMJ Open Sport and Exercise Medicine, 4(1), 17. https://doi.org/10.1136/bmjsem-2017-000314

Kimura, Y., Ohji, S., Nishio, N., Abe, Y., Ogawa, H., Taguchi, R., Otobe, Y., \& Yamada, M. (2020). The Impact of Wheelchair Propulsion Based Physical Activity on Functional Recovery in Stroke Rehabilitation: A Multicenter Observational Study. Disability and Rehabilitation, O(0), 1-6. https://doi.org/10.1080/09638288.2020.1821249 
Kramer, S. F., Hung, S. H., \& Brodtmann, A. (2019). The Impact of Physical Activity Before and After Stroke on Stroke Risk and Recovery: a Narrative Review. Current Neurology and Neuroscience Reports, 19(6). DOI:10.1007/s11910-019-0949-4

Kuriakose, D., \& Xiao, Z. (2020). Pathophysiology and Treatment of Stroke: Present Status and Future Perspectives. Int J Mol Sci, 21(20), 7609. DOI: 10.3390/ijms21207609

Le-Danseur, M. (2019). Stroke Rehabilitation. Critical Care Nursing Clinics of North America. doi:10.1016/j.cnc.2019.11.004.

Lee, J., \& Stone, A. J. (2019). Combined Aerobic and Resistance Training for Cardiorespiratory Fitness, Muscle Strength, and Walking Capacity after Stroke: A Systematic Review and Meta-Analysis. Journal of Stroke and Cerebrovascular Diseases, 104498. doi:10.1016/j.jstrokecerebrovasdis.2019.104498

Lin, F. H., Yih, D. N., Shih, F. M., \& Chu, C. M. (2019). Effect of Social Support and Health Education on Depression Scale Scores of Chronic Stroke Patients. Medicine, 98(44), e17667. DOI:10.1097/md.0000000000017667

Linder, S. M., Davidson, S., Rosenfeld, A., \& Lee, J. (2020). Forced and Voluntary Aerobic Cycling Interventions Improve Walking Capacity in Individuals With Chronic Stroke. Archives of Physical Medicine and Rehabilitation, 102(1). DOI:10.1016/j.apmr.2020.08.006

Lund, C., Dalgas, U., Grønborg, T. K., Andersen, H., Severinsen, K., Riemenschneider, M., \& Overgaard, K. (2018). Balance and Walking Performance are Improved after Resistance and Aerobic Training in Persons with Chronic Stroke. Disability and Rehabilitation, 40(20), 2408-2415. https://doi.org/10.1080/09638288.2017.1336646

Mairami, F. F., Warren, N., Allotey, P. A., \& Reidpath, D. D. (2019). Contextual factors that shape recovery after stroke in Malaysia. Disability and Rehabilitation, 42(22), 31893198. DOI: 10.1080/09638288.2019.1588399

Marzolini, S., Oh, P., Mcllroy, W., \& Brooks, D. (2012). The Effects of an Aerobic and Resistance Exercise Training Program on Cognition Following Stroke. Neurorehabilitation and Neural Repair, 27(5), 392-402. https://doi.org/10.1177/1545968312465192

Misawa, J., \& Kondo, K. (2019). Social Factors Relating to Depression Among Older People in Japan: Analysis of Longitudinal Panel Data from The AGES Project. Aging and Mental Health, 23(10), 1423-1432. https://doi.org/10.1080/13607863.2018.1496225

Moucheboeuf, G., Griffier, R., Gasq, D., Glize, B., Bouyer, L., Dehail, P., \& Cassoudesalle, H. (2020). Effects of Robotic Gait Training after Stroke: A Meta-Analysis. Annals of Physical and Rehabilitation Medicine, 63(6), 518-534. https://doi.org/10.1016/j.rehab.2020.02.008

Nam, C., Zhang, B., Chow, T., Ye, F., Huang, Y., Guo, Z., \& Li, W. (2021). Home-Based SelfHelp Telerehabilitation of the Upper Limb Assisted by an Electromyography-Driven Wrist/Hand Exoneuromusculoskeleton after Stroke. Neuroengineering and Rehabilitation, 1(18), 137. doi.org/10.1186/s12984-021-00930-3

National Institute of Neurological Disorders and Stroke. (2021). Stroke Information Page. https://www.ninds.nih.gov/Disorders/All-Disorders/Stroke-Information-Page 
Paprocka-Borowicz, M., Wiatr, M., Ciałowicz, M., Borowicz, W., Kaczmarek, A., Marques, A., \& Murawska-Ciałowicz, E. (2021). Influence of Physical Activity and SocioEconomic Status on Depression and Anxiety Symptoms in Patients after Stroke. International Journal of Environmental Research and Public Health, 18(15). https://doi.org/10.3390/ijerph18158058

Sandberg, K., Kleist, M., Falk, L., \& Enthoven, P. (2016). Effects of Twice-Weekly Intense Aerobic Exercise in Early Subacute Stroke: A Randomized Controlled Trial. Archives of Physical Medicine and Rehabilitation, 97(8), 1244-1253. https://doi.org/10.1016/j.apmr.2016.01.030

Schnitzler, A., Jourdan, C., Josseran, L., Azouvi, P., Jacob, L., \& Genêt, F. (2019). Participation in Work and Leisure Activities after Stroke: A National Study. Annals of Physical and Rehabilitation Medicine, 62(5), 351-355. https://doi.org/10.1016/j.rehab.2019.04.005

Schwarz, B., Claros-Salinas, D., \& Streibelt, M. (2018). Meta-Synthesis of Qualitative Research on Facilitators and Barriers of Return to Work After Stroke. J Occup Rehabil, 28(1), 28-44. DOI: 10.1007/s10926-017-9713-2

Stroke Association (2020). Guidelines Stroke. https://www.stroke.org/

Taylor-Piliae, R. E., Zeimantz, M. A., Dolan, H., \& Rosenfeld, A. G. (2020). Stroke Survivors' Feelings and Perceptions of Their Recovery After a Tai Chi Exercise Intervention: A Qualitative Descriptive Study. The Journal of Cardiovascular Nursing, 35(5), 468-474. https://doi.org/10.1097/JCN.0000000000000667

Vahlberg, B., Cederholm, T., Lindmark, B., Zetterberg, L., \& Hellström, K. (2016). ShortTerm and Long-Term Effects of a Progressive Resistance and Balance Exercise Program in Individuals with Chronic Stroke: A Randomized Controlled Trial. Disability and Rehabilitation, 39(16), 1615-1622. DOI:10.1080/09638288.2016.12066

Vahlberg, B., Lundström, E., Eriksson, S., Holmbäck, U., \& Cederholm, T. (2020). Effects on Walking Performance and Lower Body Strength by Short Message Service Guided Training after Stroke or Transient Ischemic Attack (The Strokewalk Study): A Randomized Controlled Trial. Clinical Rehabilitation, 35(2), 276-287. DOI:10.1177/0269215520954346

Winstein, C. J., Stein, J., Arena, R., Bates, B., Cherney, L. R., Cramer, S. C., \& Zorowitz, R. D. (2016). Guidelines for Adult Stroke Rehabilitation and Recovery. Stroke, 47(6), e98e169. doi:10.1161/str.000000000000009

Xie, G., Rao, T., Lin, L., Lin, Z., Xiao, T., Yang, M., \& Chen, L. (2018). Effects of Tai Chi Yunshou Exercise on Community-Based Stroke Patients: A Cluster Randomized Controlled Trial. European Review of Aging and Physical Activity, 15(1). doi:10.1186/s11556-018-0206-x

Zhang, W., Liu, Y., Yu, J., Zhang, Q., Wang, X., Zhang, Y., Gao, Y., \& Ye, L. (2021). Exercise Interventions for Post-Stroke Depression. Medicine, 100(8), e24945. https://doi.org/10.1097/md.0000000000024945

Zhang, Q., Schwade, M., Smith, Y., Wood, R., \& Young, L. (2020). Exercise-Based Interventions for Post-Stroke Social Participation: A Systematic Review and Network Meta-Analysis. International Journal of Nursing Studies, 111, 103738. https://doi.org/10.1016/j.ijnurstu.2020.103738 